Reseña de investigación denominada

\title{
Procedimientos Legales y Técnicos a considerar en la disolución y liquidación de una sociedad anónima (Recensión)
}

Por: Oscar Armando Melgar y Carlos Emilio Moreno

Al llevar a feliz término la realización de esta investigación, que al inicio la consideramos un reto y un desafío, en seguida la convertimos en una gran oportunidad, porque el tema conforme se fue desarrollando lo asimilamos como una cuestión de interés nacional, depositamos este producto de apoyo valioso como herramienta de consulta en las manos de docentes, estudiantes, accionistas, profesionales y otros usuarios de la información financiera.

$\mathrm{L}$

a finalidad del equipo de trabajo era dar un aporte a la sociedad dentro de la compleja extensión del área de contaduría pública con el apoyo de la Escuela de economía y negocios. Es de hacer notar que la Escuela, siempre se ha caracterizado brindar aportes académicos a diversos sectores relacionados con la investigación y estudio fenómenos propios del país; para tal fin se elaboró el documento basado en literatura legal y técnica actualizada, de manera que ése sirva como un guía de orientación, para llevar a cabo el proceso de extinción de una empresa; evitando para el comerciante acumulación de impuestos, no solventar las obligaciones económicas de la

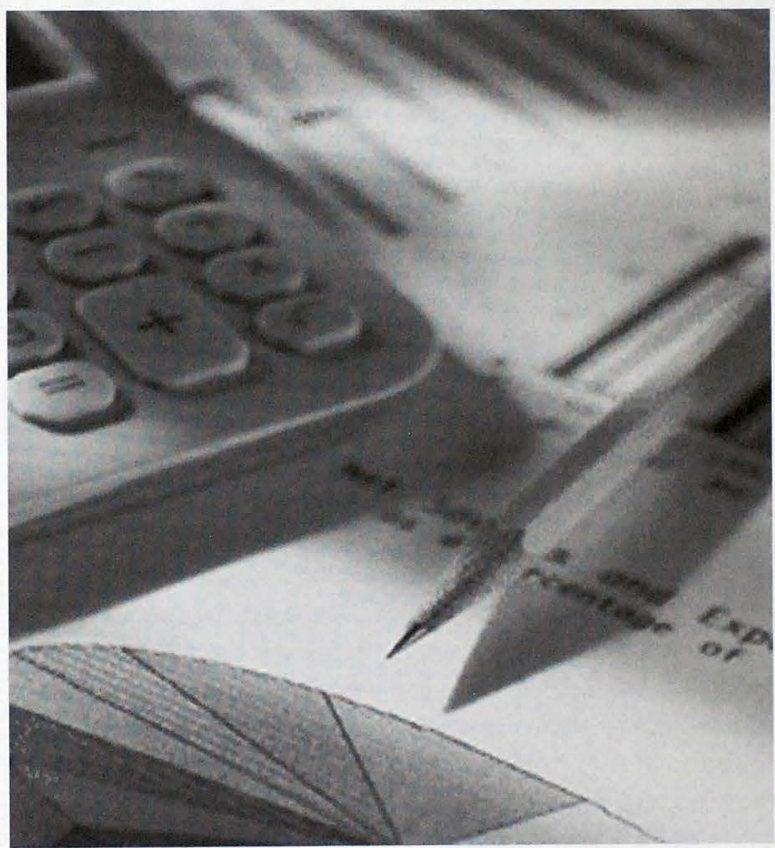


sociedad y que no se distribuya el patrimonio entre los accionistas; para el gobierno gastos innecesarios y falsas estadísticas.

La investigación se dividió en tres capítulos, a los cuales denominamos Capítulo I, marco de referencia, en el que se incluye una breve historia de las sociedades anónimas desde sus orígenes, evolución, su desempeño en la economía como instrumento de las sociedades de capital, debido al tipo de responsabilidad de los accionistas, permite la inversión de grandes capitales para la constitución de muchas empresas, contribuyendo asi a la circulación de la riqueza del país. Se adopta una definición, explicamos la forma de constitución de este tipo de sociedad. También contiene una referencia histórica sobre disolución, que se entenderá por la misma, las causales de disolución y su explicación vistas desde el punto de vista de la ley mercantil de El Salvador; asimismo se exponen las generalidades sobre la liquidación, su definición, después se hace un breve estudio y análisis del Código de Comercio en lo que respecta al proceso de liquidación, explicando el resultado con ganancia o pérdida, se incluye la ilustración de los efectos que tiene la disolución y la liquidación, con relación a la sociedad, accionistas, ante terceros y acreedores.

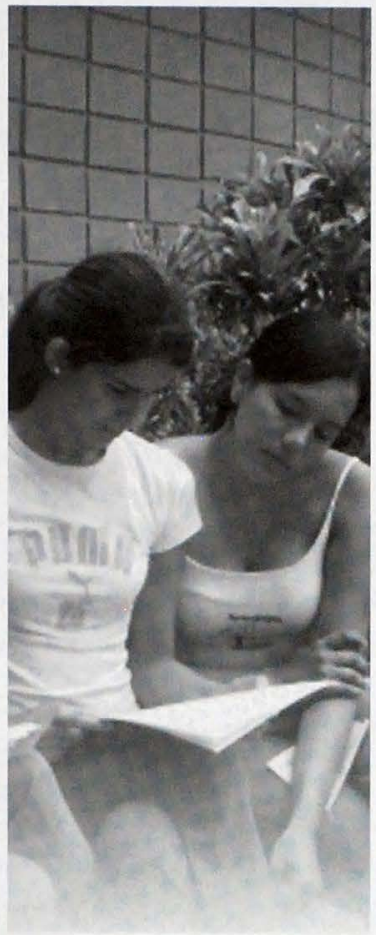

Asimismo, se integra los conceptos básicos de la información financiera que tienen incidencia en el tema en estudio, las bases contables de liquidación, la determinación de los activos y pasivos netos en liquidación, el correspondiente registro de operaciones de liquidación, la liquidación de los accionistas, las fases del proceso contable, plan de cuentas y modelo contable para este suceso económico, finalizando con la exposición del procedimiento legal a seguir cuando una sociedad se decide disolver por acuerdo 0 reconocimiento voluntario.
El capítulo II, es la investigación de campo, en éste se describen los objetivos de la investigación, tanto los generales como específicos, describimos el tipo de investigación a la cual se le ha considerado univariada; para el desarrollo de este trabajo se realizaron dos tipos de investigación, una documental y otra de campo; la población considerada para efectuar la investigación, fue la información proporcionada por el registro académico de la UTEC, la cual según sus cuadros estadísticos asciende a 101 estudiantes de los cuales 3 estudiantes aparecen como materia retirada, quedando una población real de 98 estudiantes. Por lo tanto, de la población seleccionada, consistente en 98 estudiantes, se tomó una muestra al azar, teniendo como base el listado facilitado por el registro académico de la UTEC, y a la vez considerando que cada uno de los estudiantes que conforma la población tenía la misma probabilidad de ser seleccionado y poseia las características objeto de análisis. Por ello se utilizó la fórmula para una muestra probabilística para poblaciones numerables finitas siguiente:

$n^{1}=\frac{Z^{2} P Q N}{(N-1) E^{2}+Z^{2} P Q}$

En donde:

$\mathrm{n}^{1}$ = tamaño de la muestra

$\mathrm{N}=$ universo

$\mathrm{P}=$ probabilidad de éxito 
$Q=$ probabilidad de fracaso

$\mathbf{Z}=$ nivel de confianza

$\mathrm{E}=$ error muestral

Al sustituirla originalmente se obtuvo un resultado de 60 estudiantes, los investigadores consideraron reducir la muestra, por lo cual se utilizó la fórmula de ajuste de muestra:

$n=$

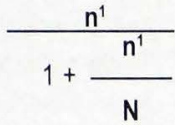

Obteniendo un nuevo resultado de 37 estudiantes a encuestar.

Los resultados de la investigación, se presentan a través de la estructura siguiente:

- Sección

- Objetivo

- Preguntas

- Alternativas u opciones, resultado y porcentajes

- Gráfico de pastel

- Interpretación
Finalmente, se presenta una serie de conclusiones y recomendaciones. A manera de ejemplo:

\section{Conclusiones}

\section{General}

El perfil del estudiante de Licenciatura en Contaduría Pública de la Universidad Tecnológica de El Salvador, debe especializarse de acuerdo al mercado laboral; dentro de esto se encuentra mostrar competitividad en el tema de estudio, a la filosofía de éste centro de estudios y sobre la correspondencia que existe en el plan de estudios; por lo tanto, tiene que contribuir a realizar la misión y visión institucional.

\section{Específicas}

- Se determinó que la dificultad que se presenta en las dependencias gubernamentales de registro que intervienen en el proceso legal de disolución y liquidación de sociedades anónimas es la lentitud de los trámites en las citadas instituciones.

- El total de los estudiantes consultados, manifiestan que es importante realizar un estudio completo sobre el proceso de disolución y liquidación de sociedades anónimas que contengan casos prácticos con la finalidad de que este sirva de guia y orientación a los accionistas, estudiantes, profesionales en contaduria pública y otros usuarios de la información financiera.

- La planificación curricular en el área de conocimientos, nace de una investigación, de acuerdo a las necesidades laborales, lo que constituye un indicativo de la rigurosidad científica del proceso educativo, contribuyendo a realizar la misión de la

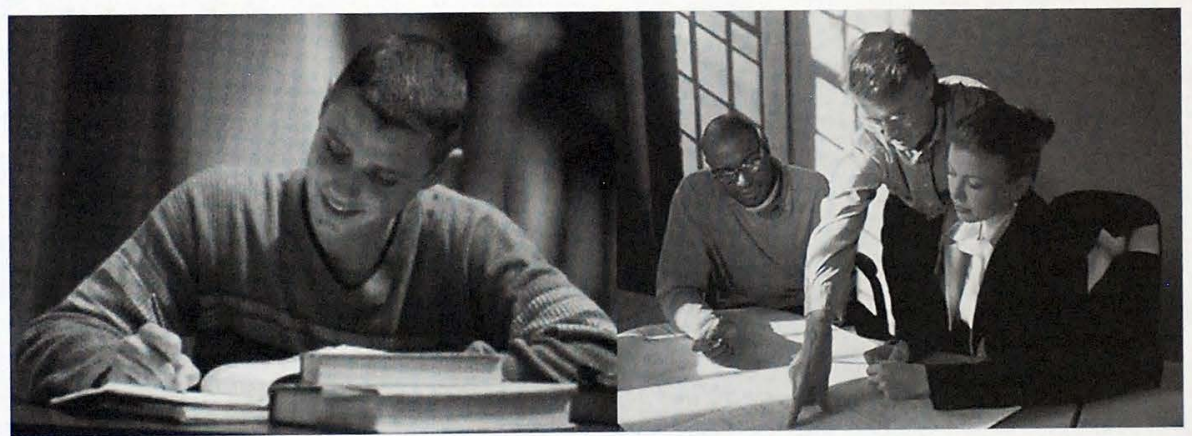




\section{Universidad Tecnológica de El Salvador.}

\section{Recomendaciones}

\section{General}

Formar en el educando el hábito de la investigación, debido a que existen temas de interés empresarial que se vuelve de pais; tal es el caso, que de no disolverse y liquidarse una sociedad anónima, se vuelve inactiva, para el comerciante significa acumulación de impuestos, no solventar las obligaciones económicas de la sociedad y que no se distribuya el patrimonio entre los accionistas, para las instituciones estatales gastos innecesarios y falsas estadisticas.

\section{Específicas}

- Las dependencias gubernamentales involucradas en el proceso de disolución y liquidación de sociedades anónimas en El Salvador, requieren de un estudio sobre los procedimientos establecidos para realizar los trámites legales en estas oficinas, con la finalidad de evaluar los ya existentes y mejorarlos, o de implementar mecanismos ágiles, prácticos y oportunos; de manera que contribuyan a la realización del proceso de extinción de una entidad y

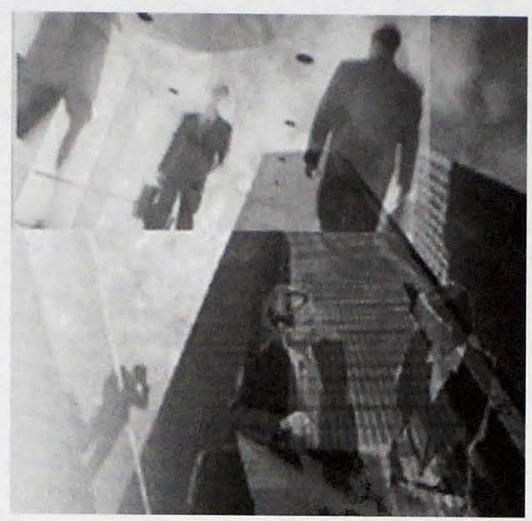

En el Capítulo III, presentamos un caso práctico, de disolución y liquidación de una sociedad anónima, en el cual se ha detallado el procedimiento legal $y$ contable en forma cronológica y ordenada; de tal manera que en el futuro sirva de guía de orientación para la realización de casos reales. El caso

disponer al contribuyente a que cumpla con las obligaciones que el marco legal establece.

- Es de relevancia destacar que la muestra total consultada, manifestó su aprobación sobre efectuar un estudio completo sobre el proceso de disolución y liquidación de sociedades anónimas, para que éste se convierta en una guía de orientación a los accionistas, estudiantes, profesionales en contaduría pública y otros usuarios de la información financiera.

- El área de conocimientos, debe estar armonizado a las nuevas necesidades, tomando en consideración los conceptos de actualización y proyección a futuro de los conocimientos a impartir, para que la profesión se perciba como verdaderamente útil. práctico elaborado, está basado en datos reales de una sociedad anónima, que decide retirarse por la situación actual en el país y por la llegada de productos del exterior que han saturado el mercado con precios menores a los de la empresa en estudio, generando mayor competencia y a la vez resultando en los dos últimos ejercicios económicos pérdidas. Por lo tanto, los accionistas de la sociedad que sirvió de base, toman el acuerdo de disolución en forma voluntaria, de acuerdo a lo estipulado en el articulo 187, romano IV, del Código de Comercio, para su posterior liquidación. La propuesta contiene modelos de actas, contrato de prestación de servicios profesionales de auditoria financiera y fiscal, plan de liquidación de la sociedad, modelos de estados financieros, entre otros. Sugeridos por los investigadores basados en la normativa técnica, marco legal y en su trayectoria en el campo laboral. 